\title{
Problems and Countermeasures of Sports Dance Course in Dance Colleges in Heilongjiang Province
}

\author{
Cong Yongzhu, Li Jingbo, Zhang Dacheng, and Ding Shiwei \\ Heihe College, Heilongjiang, China
}

Keywords: sports dance; the present situation of the course; analysis

\begin{abstract}
Sports dance, which integrates sports and art as one, is a sports course with the fusion of two kinds of sports, which is entertaining. Therefore, the teaching method should be distinguished from the traditional sports. In recent years, sports dance has been popularized in colleges and universities, which has played a positive role in the growth of college students' physical and mental health, and has become an important course in strengthening physique and aesthetic education. However, there are many problems to be solved in the course of specific development. This paper focuses on the analysis of the problems and tries to find out the corresponding solutions to further improve the quality of the teaching of sports dance. Sports dance was introduced into China in the middle of the 80s of last century, and it has been popularized rapidly. After the middle of $90 \mathrm{~s}$, it has entered the college physical education class, which is very popular among college students. This paper, through the analysis of the value of sports dance to people's exercise, investigates the development of sports dance lessons in ordinary colleges and universities in Heilongjiang, including the students' attitude to the present situation of the teaching, the situation of the facilities, the status of the teachers, and the status of the organization and the school management, analyzes the factors that influence the development of sports dance in colleges and universities in Heilongjiang, and finds out the reform measures and development strategies suitable for college sports dance development.
\end{abstract}

\section{Introduction}

Nowadays, the general colleges and universities are in the tide of the reform of physical education curriculum. The reform of school sports can not only be limited to the physical education of the school, but also should pay attention to the physical education of the people from the macro perspective. We should have the idea of guiding the course, and uphold the concept of "health first", and try to build a set of curriculum system that can adapt to the goals of ordinary colleges and universities through the research of scientific research. This is a new century, sports has been an important part of every country and every national cause, and the spirit of sports has long been the connotation of national spirit. Nowadays, many countries have used sports as an important means to improve national quality, inspire national spirit and promote social and economic development. College students are the future of the motherland. The rational and effective implementation of the physical education curriculum reform, training a large number of sports reserve talents and Cultivating College Students' lifelong physical education consciousness, has a far-reaching impact on the socialist economic construction, the physical and mental health of the whole people, the development and expansion of the sports industry.

\section{Characteristics of Sports Dance}

Sports dance, which has both sports and artistic features, belongs to the sports performance project which is evolved from the dance in the category of literature and art. It is usually for the purpose of competition and is entertaining and performing and ornamental. The characteristics of sports dance can be roughly summed up in 5 aspects: Happy fitness, sports dance rich in the entertainment and leisure of modern people, can bring joy, comfort and beauty; behavior standard, strict behavior 
standard, can not be arbitrary; comprehensive artistic, embodied in dance, music, human making. In a variety of artistic forms, tacit coordination mainly refers to the movements and tacit cooperation between the dancers and the dancers; the popularity, sports dance is a type of dance item that is easy to popularize, which is related to many kinds of dance and good safety.

According to the survey, it is found that most students who learn sports dance do not have a correct understanding of the sports dance, to be more precise, they lack an aesthetic view of the art. Physical education students in Colleges and universities have a certain sports basis, lack of basic skills in dance learning. Threfore, in their view, sports dance is only a single sport, learning this course is only to complete the learning task, the lack of aesthetic understanding. In addition, for the elective students, the study of sports dance is driven by interest, and it is very serious. For this part of the students, sports dance is to make time, or to earn credit, or to enhance the body. In view of the above two types of students, the two types of students do not feel and examine the art from the aesthetic point of view, and do not realize that the students' aesthetic ability can be promoted by the study of this course. Therefore, students in the study of sports dance, simply show the dance skills, sports dance aesthetic expression is almost ignored.

\section{The Main Problems of Sports Dance Teaching in Colleges and Universities in Heilongjiang}

\subsection{The weak students' sense of music hindering the progress of sports dance teaching}

Music is the foundation for the cultivation of physical education, music and sports dance are indispensable complement each other. If a high quality sports dance does not match with music, it will be dull, monotonous and boring, and its teaching effect will be greatly reduced. For most of the students studying sports dance, the biggest difficulty is not the action itself, but whether the dance moves in concert with the music. This situation is mainly due to the lack of systematic music training for college students. The appreciation and understanding of the poor music ability and the poor sense of music are bound to hinder the progress of sports dance teaching. Therefore, the cultivation of the sense of music is an important part of the learning and teaching process of sports dance.

\subsection{The poor basic skills impeding the improvement of teaching effect}

The basic skill for dancing is the basic skills. It refers to coordinating dance movements with its own power. For example, in the study of Latin dance, the basic skills that students must master are crotch movements, and the crotch movements are needed in all 5 Latin dances, so the importance of striding moves is self-evident. In the specific sports dance teaching, the students' interest in basic skills is not very important. They pay much attention to how to walk at the feet, how to jump and enjoy the rhythmic dance. It can be said that these problems are the primary solution and adjustment problems in the teaching process.

\subsection{Lack of students' aesthetic consciousness of sports dance}

According to the survey, it is found that most students who learn sports dance do not have a correct understanding of the sports dance, to be more precise, they lack an aesthetic view of the art. Physical education students in Colleges and universities have a certain sports basis, lack of basic skills in dance learning. Therefore, in their view, sports dance is only a single sport, learning this course is only to complete the learning task, the lack of aesthetic understanding. In addition, for the elective students, the study of sports dance is driven by interest, and it is very serious. For this part of the students, sports dance is to make time, or to earn credit, or to enhance the body. In view of the above two types of students, the two types of students do not feel and examine the art from the aesthetic point of view, and do not realize that the students' aesthetic ability can be promoted by the study of this course. Therefore, students in the study of sports dance, simply show the dance skills, sports dance aesthetic expression is almost ignored. 


\section{Countermeasures of Sports Dance Teaching in Colleges and Universities in Heilongjiang}

\subsection{To strengthen the cultivation of students' sense of music}

College physical education is mostly based on practice courses, theoretical courses are few, or even no theoretical courses. In view of this, in the teaching of sports dance, teachers can appropriately increase the course of the theoretical knowledge of the basic music courses. By understanding the students' music preferences, they teach students the music melody, rhythm and style of the dance in a planned way. The music of different kinds of dance is different, so that students can understand the music of different kinds of dance. Type. In addition, we teach students to experience the amplitude of sports dance and the interest of dancers according to the rhythm of music. Teach students a number of rhythms, answer the students' problems in time, and urge the students to practice. Finally, the students can improve the sense of music and integrate the dance skills with the music.

\subsection{To strengthen basic skills}

Sports dance teachers should establish a strong training system for basic skills, so that training can be followed in a scientific and systematic way. The students who learn sports dance are more anxious to succeed, and want to be in place. At this time, the teacher should have enough patience to help the students to explain the essentials of the movement, starting with the original basic skills training. As the practice of basic skills is rather boring and boring, teachers should act as a good guide, encourage and guide students, and allow students to carry out basic skills in a pleasant atmosphere.

Strengthen the cultivation of students' aesthetic ability. Under the influence of traditional sports concept, teachers and students' understanding of sports dance focuses too much on competitive sports, ignoring the importance of dance art. Therefore, in order to give full play to the aesthetic education function of the sports dance and to carry out the teaching better, we should first set up a correct understanding of the sports dance and improve the students' aesthetic consciousness under the guidance of the knowledge. Sports dance is both artistic and artistic. It is an artistic performance. High quality sports dance needs to show artistic beauty. The expression of aesthetic feeling of art requires performers to have better aesthetic ability, because the aesthetic and expressive ability are complementary, the more aesthetic and expressive the strength of the aesthetic power. Teachers should select the classical dance works to lead the students to appreciate, fully feel the connotation of sports dance, and let the students realize the importance of aesthetic ability in the study of sports dance. In the process of learning, students deliberately cultivate aesthetic experience and improve their aesthetic ability.

Improve the quantity and quality of sports dance teachers. The emergence of Sports Dance Majors in Colleges and universities is relatively short, and the enrollment expansion of colleges and universities has led to the shortage of sports professional dance teachers. In order to solve this problem, colleges and universities should actively introduce relevant professional graduates. In addition, we can improve the professional quality of sports dance teachers by the way of directional cultivation, and make the team of dance teachers strengthened. Under the current planning, we can train dance teachers, send physical education teachers to professional learning, so that teachers' professional ability has been targeted to improve.

Sports dance is a kind of art form. The unique value of fitness and heart is fully improved and recognized, and the students' aesthetic and aesthetic quality can be improved while improving the students' sports skills. However, as a comprehensive course, sports dance teaching will inevitably arise in the course of development. Therefore, colleges and universities should pay more attention to the development of sports dance to provide a healthy development environment and train a batch of qualified sports dance talents.

\section{Conclusion}

There are a considerable number of sports dance teachers not professional origin, the level of physical and dance teachers in various colleges and universities is not homogeneous, the teachers' 
strength needs to be further improved; the teaching materials used in the teaching of sports dance class are diverse, there are no unified teaching materials and syllabuses, and the teaching time of sports dance classes in Colleges and universities is not unified; the teaching field of sports dance class is not unified. In the dance class, the proportion of men and women is not equal, it is not conducive to the teaching, the sports dance between colleges and universities is poor and the activities in school are rarely carried out, and the proportion of sports dance classes in Shanghai colleges and universities is low. The development trend is still not balanced.

\section{Acknowledgements}

This thesis is a research project of Heilongjiang art and science planning project "(the problems and Countermeasures of the dance courses in the dance major of the general higher schools in Heilongjiang province " (project number: 2016D048)"

\section{References}

[1] Liu yun. "My view on the protection of the contemporary folk dance of our country". Journal of Minzu University of China (PHILOSOPHY AND SOCIAL SCIENCE EDITION), fifth 2004, 84 86.

[2] Zhao y. Yan. An attempt to introduce the original dance in the folk dance course in normal universities. The Journal of Yibin University is in 2009 eleventh, 124 - 126.

[3] Liqing, Xiao Ling. The construction of the local dance course from the exploitation and utilization of the Nuo resources of Jiangxi. Journal of Beijing Dance Academy, second phase of 2010, 96 - 98.

[4] Shao K. Chinese folk dance move on cultural heritage J. Journal of Beijing Dance Academy, 2002 (1): 29. 